\title{
Breaking bad news without breaking trust: The effects of a press release and newspaper coverage on perceived trustworthiness
}

\section{Stephan Grimmelikhuijsen*, Femke de Vries ${ }^{\dagger}$ Wilte Zijlstra ${ }^{\ddagger}$}

\begin{abstract}
Can a government agency mitigate the negative effect of "bad news" on public trust? To answer this question, we carried out a baseline survey to measure public trust five days before a major press release involving bad news about an error committed by an independent regulatory agency in the Netherlands. Two days after the agency's press release, we carried out a survey experiment to test the effects on public trust of the press release itself as well as related newspaper articles. Results show that the press release had no negative effect on trustworthiness, which may be because the press release "steals thunder" (i.e. breaks the bad news before the news media discovered it) and focuses on a "rebuilding strategy" (i.e. offering apologies and focusing on future improvements). In contrast, the news articles mainly focused on what went wrong, which affected the competence dimension of trust but not the other dimensions (benevolence and integrity). We conclude that strategic communication by an agency can break negative news to people without necessarily breaking trust in that agency. And although effects of negative news coverage on trustworthiness were observed, the magnitude of these effects should not be overstated.
\end{abstract}

Keywords: Public trust, News media, Regulation, Strategic communication, Survey experiment

$\mathrm{M}$ any scholars in public administration and communication acknowledge the importance of communicating with the public to sustain citizen trust and legitimacy (Fairbanks, Plowman, \& Rawlins, 2007; Liu, Horsley, \& Blake, 2010; Liu, Horsley, \& Yang, 2012; Ruijer, 2013). One core idea behind proactive communication is that it can be used to counterbalance negative media coverage (Graber, 2003; Liu et al., 2012). But are proactive forms of communication by public organizations effective for this purpose?

There is an abundance of research on how media coverage and framing of political issues affect public opinion (e.g. Chong \& Druckman, 2007;

\footnotetext{
* Utrecht University School of Governance, The Netherlands;

† Department of Constitutional, Administrative law and Public Administration, University of Groningen, The Netherlands; \&samhoud consultancy;

$\ddagger$ Dutch Authority for the Financial Markets (AFM), The Netherlands

Address correspondence to Stephan

Grimmelikhuijsen at (s.g.grimmelikhuijsen@uu.nl)

Copyright: C 2018. The authors license this article under the terms of the Creative Commons Attribution 4.0 International License.

Updated with minor corrections on 5/21/2018
}

Slothuus \& De Vreese, 2010) and how crisis communication affects organizational reputations (e.g. Coombs, 2007; Arpan \& Roskos-Ewoldsen, 2005). But there is scarce empirical research directly investigating the effect of press releases of public organizations, and particularly independent regulatory agencies (IRAs), on citizen trust. Communication for public organizations has some likening with private sector communication, but there are fundamental differences related to unique government functions such as informing the public and raising awareness (Pasquier, 2017). In addition, studies in crisis communication have mostly investigated effects in a fairly controlled setting (e.g. Arpan \& Roskos-Ewoldsen, 2005; Coombs \& Holladay, 2008; Claes, Cauberghe,\& Vincke, 2010). In contrast, we take our experiment into the field and study a real-world organization faced with the challenge of communicating bad news to the public. Finally, empirical studies from public administration on the effects of communication are scarce. Some studies have found positive associations between proactive communication and citizen attitudes, but these studies did not rely on experimental data and thus have limited causal validity (Liu et al., 2012; Hong, 2016). 
To fill this gap, we carried out an experiment using a real press release and news media articles focusing on errors in supervision made by an independent regulatory agency. Why do we focus specifically on a mistake by an independent regulatory agency (IRA)? First, we think that errors, as opposed to successes, have more influence on public perceptions because media coverage tends to focus on what went wrong (Liu et al., 2010; Jacobs \& Schillemans, 2016) and negative information tends to have a stronger effect on judgments (e.g. Olsen, 2015). Secondly, this kind of communication is important because it functions as an informal accountability mechanism. Jacobs and Schillemans (2016) have found that public organizations, in anticipation of potential media scrutiny, exert "preemptive self-criticism," meaning that agencies disclose failure themselves before it is revealed by the media. Thirdly, we focus on an IRA because these agencies face a somewhat less adversarial media environment than some other government institutions (Maggetti, 2012, p. 400; Van Erp, 2013; Glynn \& Huge, 2014; Puppis, Maggetti, Gilardi, Biela, \& Papadopoulos, 2014) and therefore citizens may be more amenable to information coming from a relatively independent government agency, as opposed to organizations less independent from politics.

Specifically, we test the effect of a major press release by the Dutch Authority for Financial Markets (AFM) and subsequent newspaper coverage in an experiment. ${ }^{1}$ The AFM is an IRA regulating the financial markets in the Netherlands. We had the unique foreknowledge of the release date of an upcoming press release and related attention from news organizations. A few days before the press release came out, we carried out a pre-test to measure citizen trust in the AFM. Then the agency issued a press release and held a press conference. A week after the pre-test, we carried out a post-test survey in which various treatments were embedded (the press release, three media articles on the AFM and its supervision error, and a control group). We also controlled for natural exposure to news about the failure. Our results show a negative effect of the news media articles on perceived competence of the AFM, and a null effect of the press release on all dimensions of perceived trustworthiness (i.e. competence, benevolence and integrity). We conclude that the press release was effective in decreasing the potential negative effect of providing bad news to the public. Also, even though the newspaper articles were highly critical of the error of the AFM, their negative effect on trustworthiness was limited. These findings suggest that it is possible to break bad news without necessarily breaking trust.

\section{The Potential Effects of Press Releases on Citizen Trust}

As mentioned, in this study we investigate the effects of a negative press release and related newspaper articles on public trust in a Dutch IRA. How might such a press release affect the perceived trustworthiness of an IRA? Research in crisis communication has developed and tested various organizational responses to prevent reputational damage as a result of crises (e.g. Coombs, 2007). Two core elements in crisis communication that have been found to prevent reputation loss are timing and content of the message. First, self-disclosing information about a crisis helps to "steal thunder". By breaking the news about an internal crisis before it is discovered by others, an organization gains credibility and public trust (Claes \& Cauberghe, 2012; Arpan \& Roskos-Ewoldsen, 2005). In our case, the communication strategy by the AFM could be qualified as "stealing thunder"; a press release and press conference provide the news before news media can "scoop" the story. Thus the effect of a pre-emptive press release is expected to be relatively favorable.

A second reason why we expect the press release to have a relatively favorable effect on public opinion (that is, not a negative effect) is that the press release, as opposed to the related news coverage, focuses on a so-called "rebuild strategy". Such a strategy offers apologies for the crisis, which leads to more effective reputation restoration than, for instance, denying responsibility (Claeys, Caubergh \& Vyncke, 2010; Coombs \& Holladay, 2008).

In our experiment, the press release is preemptive and focuses on how the AFM attempts to improve it operations in the future to prevent the crisis from happening again. According to the above-mentioned experiments on crisis communication, this should prevent reputation loss even though it may not improve reputation either. This means that we propose essentially a null hypothesis for the press release effect:

H1: A press release does not negatively affect the perceived trustworthiness of an independent regulatory agency. 
We also take into account that many people will only hear about the AFM through news media coverage and will not directly read the press release. We test the effect of newspaper articles that were in part based on the press release. Since the articles had a much more negative tone and did not have a strong "rebuilding" focus, we expect that this coverage has a negative effect on perceived trustworthiness: ${ }^{2}$

\section{H2: News media coverage negatively affects the perceived} trustworthiness of an independent regulatory agency.

\section{Experimental Design and Methods}

\section{Experimental Design}

We compared the trust Dutch citizens have in AFM before and after a press release that would likely have (and indeed had) a large media-impact. We employed an experimental design and also exploited natural variation in our respondents as to whether or not they had read or seen news about the issue at hand. The experimental set-up is summarized in Figure 1.

All respondents received the same prepublication survey in which their pretest attitudes were measured (T0). For the post-publication survey, we randomly assigned participants to one of five experimental groups. One week later, their posttest attitudes were measured (T1). The controlgroup was not shown any additional information; their questionnaire was the same as the baseline measurement (T0). The other four groups were shown some sort of information before completing the questions for trust in the AFM. One group ("AFM") read the full press release by the AFM. The other three experimental groups read a news item that had appeared in the nationwide press. One in Het Financieele Dagblad ("FD", Dutch Financial Times, circulation 50,000), another group read an article from De Telegraaf ("Telegraaf", the largest Dutch national newspaper with a circulation of 462,000), and another experimental group got to

\section{Figure 1 \\ Overview of Experimental Design}

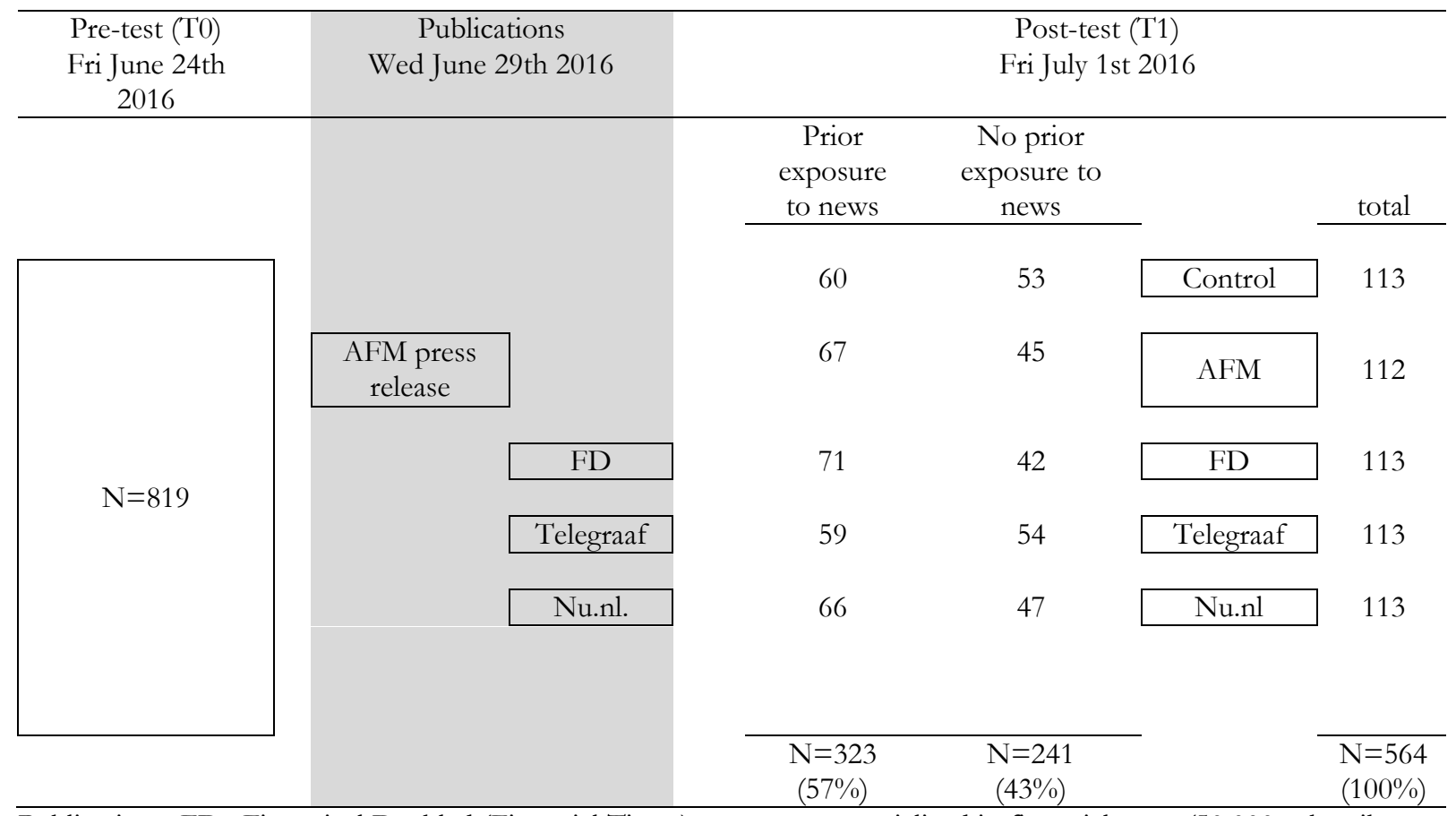

Publications: FD=Financieel Dagblad (Financial Times), newspaper specialized in financial news (50,000 subscribers), Telegraaf $=$ largest Dutch newspaper, with right leaning political orientation $(462,000$ subscribers $), \mathrm{Nu} . \mathrm{nl}=$ news website, most-read online news source in the Netherlands (7.1 million unique visitors monthly). To check for prior exposure we asked if people read any news about this topic in the preceding days. They reported to have read to following sources: Press release $15 \%$, Nu.nl 28\%, FD 17\%, Telegraaf $12 \%$. 
read an article on the Dutch news website nu.nl (this website is the largest news website in the Netherlands, attracting 2.7 million unique visitors per day). The texts used are all in Dutch and available as Appendix 2. Each of the five experimental groups consisted of $\mathrm{N}=112$ or $\mathrm{N}=113$ respondents.

In addition, all respondents were asked if they had read something about the AFM issue themselves in the past days. More than half $(57 \%)$ of respondents reported having done so. Thus, besides the experimental groups that we randomly assigned, we can also classify each respondent according to whether or not they had been informed about the AFM issue in the natural course of their own reading of the news.

\section{Data Collection}

Our respondents were drawn from the AFM Consumer panel. This panel, founded in June 2014, is a dedicated, online panel that the AFM uses to survey consumers and is operated by market research bureau GfK. The panel consists of about 1700 respondents and is not representative for the general population of the Netherlands; respondents are disproportionally more male $(81 \%$ are male), higher educated, and older $(27 \%$ are 65 years or older, mean age is 61 years). About half of the panelmembers invest in the stock market, in contrast to less than one in five for the general Dutch population. ${ }^{3}$ Although this is certainly not a representative panel, respondents in the AFM Consumer panel are, for obvious reasons, more familiar with the AFM. This contributes to ecological validity in the sense that the respondents are a group of people who are more likely to read about the AFM than the average citizen.

The baseline-measurement was completed by $n=819$ respondents. A week later, after the external publication of the AFM press release and subsequent articles in national newspapers and media, these respondents were again approached. In total, $n=564(69 \%)$ of the baseline respondents completed the follow-up survey. For each respondent, we can compare trust in the AFM before and after publication of the press release.

\section{Variables}

To measure trust in the AFM, we adapted a validated 9-item trust scale that consists of three constructs: Competence, Benevolence, and Integrity (Grimmelikhuijsen \& Knies, 2017). Items could be scored on a five-point Likert-scale ranging from "completely disagree" (1) to "completely agree" (5). The composite score for trust in the AFM is the average of the averages for Competence, Benevolence and Integrity. Items were presented in a random order. The items are listed below:

Competence ( 3 items, Cronbach's alpha at baseline $=.885$, at follow-up $=.914$ )

1. The AFM is capable.

2. The AFM is professional.

3. The AFM carries out its duties effectively.

Benevolence ( 3 items, Cronbach's alpha at baseline $=.855$, at follow-up $=.875$ )

1. If consumers need help, the AFM would do its best to help them.

2. The AFM acts in the interest of citizens.

3. The AFM is genuinely interested in the wellbeing of citizens, not just its own wellbeing.

Integrity (3 items, Cronbach's alpha at baseline $=.910$, at follow-up $=.916$ )

1. The AFM is straightforward to citizens.

2. The AFM is honest.

3. AFM is sincere.

Respondents that only completed the baseline survey ( $n=255,31 \%$ of initial sample) did not differ significantly on the trust scale from respondents that did complete the follow up survey a week later. ${ }^{4}$

\section{Results}

To test our hypotheses, we carried out a repeated measures MANOVA. The analysis included 5 groups (control, press release, and three newspaper articles) and included the effect of natural exposure to news about the failure of the AFM (natural exposure v. no natural exposure). Perceived competence, benevolence and integrity were measured prior to and after the treatment (thus repeated measures). The five experimental groups were statistically equivalent in the terms of their means for: competence $\mathrm{F}(5,559)=0.69, p=.596$; benevolence 
$\mathrm{F}(5,559)=1.65, p=.161$; and integrity $\mathrm{F}(5,559)=0.94$, $p=.438$.

Table 1 shows the differences between the pretest and posttest means for the overall sample, which includes both respondents who had and who had not been naturally exposed to the news before they received the treatments in the experiment. Of the three dimensions, perceived competence seems to be affected most strongly by being exposed to information about the failure. For perceived benevolence and integrity the differences are much smaller than for competence. The decline in the control group of -.22 can be explained by the 'exposed' respondents in the sample: 241 (43\%) respondents indicated they had not been exposed before, $323(57 \%)$ had been exposed. We will take this source of variation into account by controlling for it in subsequent analyses.

We found an overall multivariate interaction effect of our treatment with the difference between the pretest (T0) and the posttest (T1) $(F(4,554)=2.92, p<.001)$. This means that the change in trust between T0 and T1 is affected by the treatment. To provide more specific information on which treatment affects which dependent variables, we carried out subsequent repeated measures ANOVAs. Table 2 provides details of the effects of the press release on perceived competence, benevolence and integrity.

Perceived competence is most strongly affected by the treatment $(\mathrm{F}(4,554)=5.09, p<.001$, partial eta $\left.^{2}=.035\right)$. Interestingly, we find weaker treatment effects on perceived benevolence $(\mathrm{F}(4,554)=2.40, \quad p=.049) \quad$ and integrity $(\mathrm{F}(4,554)=3.23, p=.012)$. From the descriptive results in Table 1, this is a positive effect that appears most pronounced in the "Nu.nl" condition. Upon further inspection, however, we found no significant specific group differences between any of the treatment conditions and the control group on the benevolence and integrity dimensions.

Furthermore, natural exposure to the AFM issue, as opposed to experimental exposure, also has an effect but only on perceived competence $\left(\mathrm{F}(4,554)=14.95, p=.000\right.$, partial eta $\left.{ }^{2}=.026\right)$. This means that people who read about the policy

Table 1

Mean Difference between Pre-test (T0) and Post-test (T1) on Components of Trust

\begin{tabular}{lccccc}
\hline \hline & Control & Press release & Financial T & Telegraaf & Nu.nl \\
\hline Competence & -0.224 & -0.256 & -0.519 & -0.478 & -0.501 \\
Benevolence & 0.086 & -0.054 & 0.062 & 0.083 & 0.212 \\
Integrity & 0.077 & -0.048 & 0.162 & 0.038 & 0.221 \\
\hline
\end{tabular}

Table 2

ANOVA of Treatment Effects

\begin{tabular}{llccc}
\hline \hline \multicolumn{1}{c}{ Source } & \multicolumn{1}{c}{ Measure } & F & Sig. & Partial Eta Squared \\
\hline T1-T0 & Competence & 175.34 & .000 & .240 \\
& Benevolence & 7.32 & .007 & .013 \\
T1-T0 * Treatment & Integrity & 11.93 & .001 & .021 \\
& Competence & 5.09 & .000 & .035 \\
T1-T0 * Prior exposure & Benevolence & 2.40 & .049 & .017 \\
& Integrity & 3.23 & .012 & .023 \\
T1-T0 * Treatment $*$ & Competence & 14.95 & .000 & .026 \\
Prior exposure & Benevolence & 1.80 & .181 & .003 \\
& Integrity & 0.02 & .877 & .000 \\
& Competence & 0.39 & .819 & .003 \\
& Benevolence & 0.76 & .553 & .005 \\
& Integrity & 0.57 & .681 & .004 \\
\hline
\end{tabular}


Figure 2

\section{Effects of the Press Release and Newspaper Coverage on Perceived Competence}

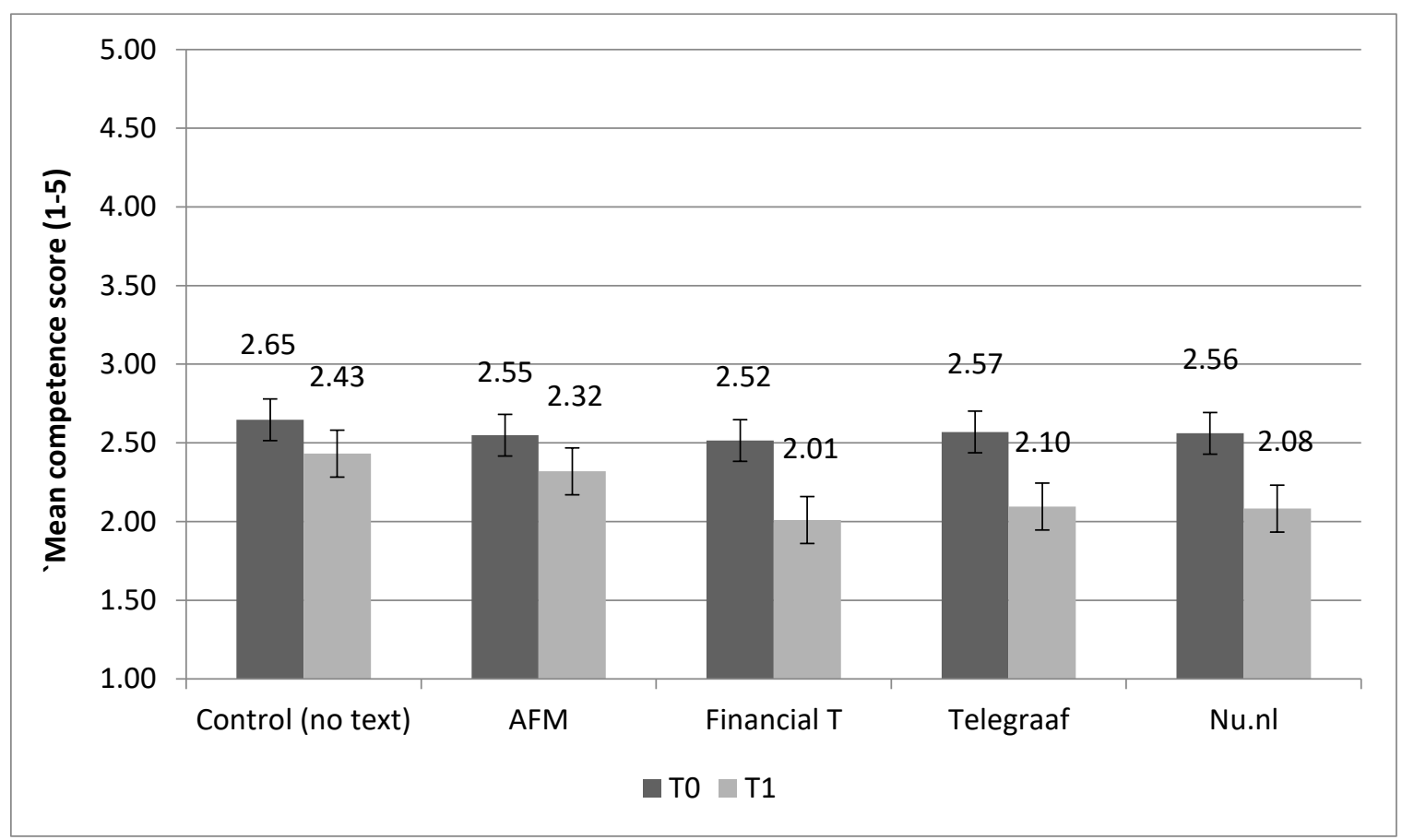

Error bars depict confidence intervals at 95\%. Covariates appearing in the model are evaluated at the following values: natural (prior) exposure $=.5727$.

failure before the post-test (T1) were significantly less trusting regarding the competence of the AFM, but not regarding benevolence and integrity. This effect is visualized in Figure 2.

As we expected, we found the press release to have no significant negative effects on perceived competence, benevolence or integrity.

The newspaper articles indeed negatively affected perceived competence. The exact content of the article did not seem to matter that much as all posttest means were within a range of 2.01 to 2.08. Figure 2 shows clearly that confidence intervals between the pretest and posttest are not overlapping, which indicates a significant difference (at $p<.05)$. The observed media coverage did not significantly affect perceived benevolence, or perceived integrity, which means we only find partial support for $\mathrm{H} 2$.

\section{Auxiliary analyses}

One often-heard criticism of survey experiments is that they are artificial and have low generalizability. Although our treatment is highly realistic, as we use a real press release and real newspaper articles, one criticism could be that in the survey experiment the press release and newspaper articles were forced on respondents, in a sense, and thus respondents might have responded differently had they encountered the same information in the ordinary course of daily life. Therefore, we performed a test using only the "natural" exposure to the news about the policy failure of the AFM. Specifically, in the posttest questionnaire, respondents were asked if they had heard about the policy failure (thus indicating natural exposure). We can use the control group only to test the association of this natural exposure to the news about AFM with perceived trustworthiness of the agency. Because natural exposure is non-random, there is of course the potential for endogeneity bias in this analysis. Therefore, this analysis should be viewed as a supplement to the main, experimental analysis.

We used participants from the control group only and divided them into a group who did $(n=60)$ and did not $(n=53)$ report that they were 


\section{Figure 3 \\ Effects of Natural Prior Exposure to Negative News on Perceived Trustworthiness (Analysis of Control Group only, $n=113$ )}

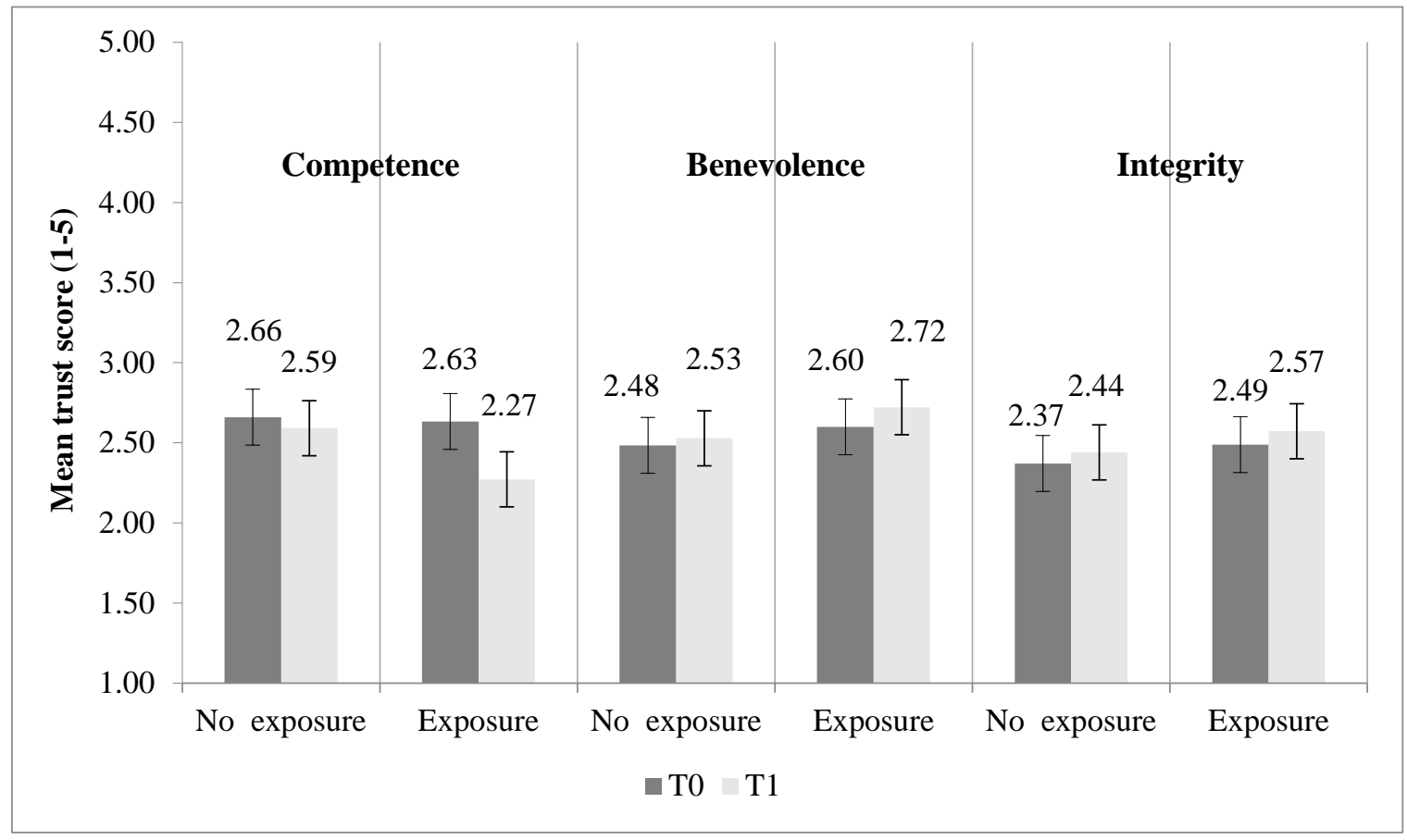

Error bars depict confidence intervals at 95\%.

exposed to the news about AFM prior to the experimental treatment. Figure 3 shows the different plots for each dimension of perceived trustworthiness. The pretest (T0) means for competence, benevolence, integrity and trust did not differ significantly between these two groups $(\mathrm{Fs}<.734$, ps $>.393)$. The overall multivariate effect of the interaction between natural exposure and the pretest and posttest measurement was significant and had a rather large effect size $(\mathrm{F}(1,109)=3.96, p=0.01$, partial eta-squared $=.098)$. This means that people who read something about the AFM policy failure prior to the post-test (T1) responded differently to questions on trust in the AFM than those without natural exposure. As Figure 3 makes clear, there is a negative effect of natural information exposure on perceived competence $(\mathrm{F}(1,111)=8.28, p=.005$, partial eta-squared $=.069)$, yet no effect on the other two dimensions. Overall natural exposure seems to have a similar effect as exposure in the more controlled experimental exposure: a negative effect on perceived competence, yet no effect on perceived benevolence or integrity.
In a final check, it can be seen that participants' self-reported change in trust aligns with the experimental effects between treatments. The selfreported change in trust (either negative, neutral or positive) correlated much more strongly with competence $(\mathrm{Rho}=-0.411, \mathrm{p}<.001)$ than with either benevolence or integrity $(\mathrm{Rho}=.176, \mathrm{p}<.001$ and Rho $=.162, \mathrm{p}<.001)$.

\section{Conclusion and Discussion}

Because of a collaboration between practitioners and academics, we were able to link an experimental set-up to a real-life event with a large media impact. We showed that negative information about an independent regulatory agency led to widespread and negative media-coverage, but did not significantly affect the public's view on the benevolence or integrity of that agency. Perceived competence was negatively affected by media coverage, but proactive communication through a press release by the public agency itself was shown to be able to mitigate that negative response. 
Empirical studies in the field of public administration that focus explicitly on communication are still relatively scarce (e.g. Fairbanks, Plowman, \& Rawlins, 2007; Liu, Horsley, \& Blake, 2010; Ruijer, 2013), with some suggesting that proactive forms of communication might act as a counterbalance to negative news exposure (Graber, 2003; Liu et al., 2012). Our experiment contributes to this growing body of literature by showing that by proactively releasing news to the press it may be possible to 'come clean' about competence-based errors without losing on other fundamental dimensions of trustworthiness, such as perceived integrity.

It should be noted though that more systematic experimental evidence is needed to be able to generalize these findings. First, we need to take into account that we focused one specific event with idiosyncrasies that might make this failure more 'suitable' for communication. The failure concerned a fairly technical issue affecting small and medium enterprise businesses, and there was no visible harm to the general public because of this failure. Furthermore, the experiment reported on what can be considered a 'competence-based' error: the AFM made judgmental errors yet its employees did not, for instance, deliberately break the rules for their personal profit. The latter would be an integrity-based crisis, which would probably affect other dimensions of perceived trustworthiness.

Another limitation stems from the fact that we use a naturally occurring event and materials in our experiment. Although this approach has the advantages of experimental realism, it comes with a loss of control over the stimulus materials. Therefore, we cannot pinpoint the exact explanatory mechanism behind our findings. For instance, we cannot tell which specific communication strategy drives the results, since both "stealing thunder" and "rebuilding" (Coombs, 2007; Clays \& Cauberghe, 2012) strategies are applied in the press release. Moreover, the source of the message varies as well (the AFM and the three newspapers), which makes the experimental design more realistic but also the results somewhat more ambiguous to interpret. Future experimental work along these lines should take this into account and try to test more abstracted treatment materials to provide insight about the precise causal mechanisms.

Finally, other types of errors could evoke more negative responses. For instance, if a health inspection fails in supervising a hospital and patients die, the responsible agency might face much stronger reputational setbacks. Thus, research into other more salient policy domains is needed to investigate the generalizability of our findings. Another area for future investigation would be to investigate the longevity of these negative effects. In our auxiliary analysis (focusing on the effect of only natural exposure to the AFM issue) we could see that the negative effect lasted at least several days. But more research is need to understand the duration of such negative effects as well as the longterm effectiveness of related pre-emptive communication strategies. From a practical point of view, our findings have some important implications; they suggest that communicating pre-emptively and openly about errors and focusing on a rebuilding strategy can help to maintain citizen trust.

\section{Notes}

1. Our study focuses on a critical report on the quality of the supervision by the AFM of interest rate swaps (IRSs). The AFM investigated these complex IRS-contracts in 2014 and announced that the banks involved had to review and compensate firms. The AFM would supervised the process, yet on the $3 \mathrm{rd}$ of December 2015 , less than a month before the deadline of the review by the banks, the AFM announced banks had made serious mistakes and that its own supervision of the review process had not been sufficiently rigorous. As a result, the review process could not be finished and customers were not compensated. Appendix 1 provides a more elaborate description of the event leading up to a highly critical independent report and the subsequent press release by the AFM.

2. We carried out a content analysis that indeed shows the difference in focus, see Supplementary materials for details.

3. http://www.tns-nipo.com/ons-aanbod/sectoren/finance/retail-investor, access February 6, 2018

4. Oneway ANOVAs on pretest results between respondents that did and did not complete posttest: Competence F1,817 $=0.541, \mathrm{p}=0.462$; Benevolence $\mathrm{F} 1,817=0.962, \mathrm{p}=0.327$; Integrity $\mathrm{F} 1,817=0.239, \mathrm{p}=0.625$; Trust $\mathrm{F} 1,817=0.631$, $\mathrm{p}=0.427$. 


\section{References}

Arpan, L.M., \& Roskos-Ewoldsen, D.R. (2005). Stealing thunder: Analysis of the effects of proactive disclosure of crisis information. Public Relations Review 31(3): 425-433

Chong, D., \& Druckman, J. (2007). Framing theory. Annual Review of Political Science 10: 103-126.

Claeys, A., \& Cauberghe, V. (2012). Crisis response and crisis timing strategies, two sides of the same coin. Public Relations Review 38(1): 83-88.

Claeys, A., V. Cauberghe, \& Vyncke, P. (2010). Restoring reputations in times of crisis: An experimental study of the Situational Crisis Communication Theory and the moderating effects of locus of control. Public Relations Review 36(3): 256262.

Coombs, W.T. (2007). Protecting Organization Reputations During a Crisis: The Development and Application of Situational Crisis Communication Theory. Corporate Reputation Review 10(3): 163-176.

Coombs, W.T., \& S.J. Holladay. (2008). Comparing apology to equivalent crisis response strategies: Clarifying apology's role and value in crisis communication. Public Relations Review 34(3): 252257.

Ennser-Jedenastik, L. (2016). The Politicization of Regulatory Agencies: Between Partisan Influence and Formal Independence. Journal of Public Administration Research and Theory 26(3): 507-518.

Fairbanks, J., Plowman, K.D., \& Rawlins, B.L. (2007). Transparency in government Communication. Journal of Public Affairs 7(1): 23-57

Glynn, C.J., \& Huge, M.E. (2014). How Pervasive Are Perceptions of Bias? Exploring Judgments of Media Bias in Financial News. International Journal of Public Opinion Research 26(4): 543-553.

Graber, D.A. (2003). The power of communication: Managing information in public organizations. Washington, DC: CQ Press.

Grimmelikhuijsen, S.G., \& Knies, E. (2017). Validating a scale for citizen trust in government organizations. International Review of Administrative Sciences 83(3): 583 $-601$.

Hong, S. (2016). Government Press Releases and Citizen Perceptions of Government Performance: Evidence from Google Trends Data. Public Performance \& Management Review 39(4): 885-904.

Jacobs, S., \& Schillemans, T. (2016). Media and public accountability: typology and exploration. Policy \& Politics 44(1): 23-40.

Lee, M. (2008). Public relations in public administration. In M. Lee (ed.), Government public relations: $A$ reader, (pp. 4-15). Boca Raton, FL: CRC Press.

Liu, B.F., J.S. Horsley, \& Yang, K. (2012). Overcoming Negative Media Coverage: Does Government
Communication Matter? Journal of Public

Administration Research and Theory 22(3): 597-621.

Liu, B.F., J.S. Horsley, \& Levenshus, A.B. (2010).

Government and Corporate Communication

Practices: Do the Differences Matter? Journal of Applied Communication Research 38(2): 189-213.

Maggetti, M. (2012). The media accountability of independent regulatory agencies. European Political Science Review 4(3): 385-408.

Marvel, J.D. (2015). Unconscious Bias in Citizens' Evaluations of Public Sector Performance. Journal of Public Administration Research and Theory 26(1): 143158.

Mayer, R.C., J.H. Davis, \& F.D. Schoorman. (1995). An Integrative Model of Organizational Trust. The Academy of Management Review 20(3): 709-734.

Mazzoleni, G., \& W. Schulz. (2001). "Mediatization" of Politics: A Challenge for Democracy? Political Communication 16(3): 247-261

McEvily, B., \& Tortoriello, M. (2011). Measuring trust in organisational research: Review and recommendations. Journal of Trust Research 1(1): 23-63

Olsen, A.L. (2015). Citizen (Dis)satisfaction: An Experimental Equivalence Framing Study. Public Administration Review 75(3): 469-478.

Pasquier, M. (2018). Communication. In E. Ongaro and S. Van Thiel (eds.) The Palgrave Handbook of Public Administration and Management in Europe (pp. Pages 441-458). London: Palgrave Macmillan.

Peters, B.G. (2016). Governance and the media: exploring the linkages. Policy \& Politics 44(1): 9-22.

Puppis, M., M. Maggetti, F. Gilardi, J. Biela, \& Papadopoulos, Y. (2014). The Political Communication of Independent Regulatory Agencies. Public Administration 20(3): 388-412

Rousseau, D., S. Sitkin, R. Burt, \& Camerer, C. (1998). Not so different after all: A cross-discipline view of trust. Acadamy of Management Review 23(3):393-404.

Ruijer, E. (2013). Proactive Transparency in the United States and the Netherlands. The Role of Government Communication Officials. American Review of Public Administration 47(3): 354-375.

Slothuus, R., \& de Vreese, C.H. (2010). Political Parties, Motivated Reasoning, and Issue Framing Effects. The Journal of Politics 72(3): 630-645.

Van Erp, J. (2013). Messy business: Media representations of administrative sanctions for corporate offenders. Law \& Society 35(1-2): 101-139.

Zerfass, A., Verhoeven, P., Tench, R., Moreno, A., \& Vercic, D. (2011). European Communication Monitor 2011. Empirical Insights into Strategic Communication in Europe. Results of a Survey in 43 Countries. Brussels: EACD/EUPRERA, Helios Media. 


\section{References to original newspaper articles (in Dutch)}

Externe onderzoekers oordelen snoeihard over optreden AFM in rentederivatendossier ("External reviewers issue harsh judgement on AFM regarding interest rate derivatives"). Het Financieel Dagblad. Last accessed at February 6, 2018, https://fd.nl/ondernemen/1158142/externeonderzoekers-oordelen-snoeihard-over-optredenafm-in-rentederivatendossier

Hard oordeel over toezichthouder in rentederivatendossier ("Harsh judgement on regulator regarding interest rate derivatives"). Nu.nl. Last accessed at February 6, 2018

http://www.nu.nl/economie/4285375/hardoordeel-toezichthouder-inrentederivatendossier.html

Flaterfestijn bij AFM ("Comedy of errors at AFM") http://www.telegraaf.nl/dft/ondernemen/2611475 3/_Flaterfestijn_bij_AFM_.html

AFM trekt lessen uit extern rapport over toetsing van rentederivatendienstverlening door banken ("AFM draws lessons from external report on assessment of advice and sales of interest rate derivatives by banks"). AFM. Last accessed at February 6, 2018: https://www.afm.nl/nlnl/nieuws/2016/jun/rapport-toetsingrentederivaten 